\title{
Obstructive sleep apnea and incidence of postoperative delirium after elective knee replacement in the nondemented elderly
}

\author{
Benjamin J. Flink, BA, \\ Student, School of Medicine, Duke University Medical Center, Durham, NC 27710
}

Sarah K. Rivelli, MD,

Assistant Professor, Department of Psychiatry and Behavioral Sciences, Duke University Medical Center, Durham, NC 27710; Assistant Professor, Department of Medicine, Duke University Medical Center, Durham, NC 27710

Elizabeth A. Cox, MD,

Resident, Department of Anesthesiology, Massachusetts General Hospital, Boston, MA 02114

William D. White, MS MPH,

Biostatistician, Department of Anesthesiology, Duke University Medical Center, Durham, NC 27710

Grace Falcone, RN,

Nurse Practitioner, Department of Psychiatry, Duke University Medical Center, Durham, NC 27710

Thomas P. Vail, MD,

Professor, Department of Orthopedic Surgery, University of California San Francisco, San

Francisco, CA 94143

Christopher C. Young, MD,

Associate Professor, Department of Anesthesiology, Duke University Medical Center, Durham, NC 27710

Michael P. Bolognesi, MD,

Assistant Professor, Department of Surgery, Duke University Medical Center, Durham, NC 27710

Andrew D. Krystal, MD,

Professor, Department of Psychiatry and Behavioral Sciences, Duke University Medical Center, Durham, NC 27710

Paula T. Trzepacz, MD,

Lilly Research Laboratories, Indianapolis, Indiana

Richard E. Moon, MD, and

Professor, Department of Anesthesiology, Duke University Medical Center, Durham, NC 27710;

Professor, Department of Medicine, Duke University Medical Center, Durham, NC 27710

Corresponding author: Madan M. Kwatra, PhD, P.O. Box, 3094, DUMC, Durham, NC 27710. Phone: (919) 681-4775; Fax: (919) 681-8089; kwatr001@mc.duke.edu.

Institution and Department: Duke University Medical Center, Department of Anesthesia

Presentations: This work was presented at annual meeting of the American Society of Anesthesiologists, October 19, 2009, New Orleans, LA

This is a PDF file of an unedited manuscript that has been accepted for publication. As a service to our customers we are providing this early version of the manuscript. The manuscript will undergo copyediting, typesetting, and review of the resulting proof before it is published in its final citable form. Please note that during the production process errors may be discovered which could affect the content, and all legal disclaimers that apply to the journal pertain. 
Madan M. Kwatra, PhD

Associate Professor, Department of Anesthesiology, Duke University Medical Center, Durham, NC 27710

\section{Abstract}

Background-Postoperative delirium, a common complication in the elderly, can occur following any type of surgery and is associated with increased morbidity and mortality; it may also be associated with subsequent cognitive problems. Effective therapy for postoperative delirium remains elusive because the causative factors of delirium are likely multiple and varied.

Methods-Patients $\geq 65$ years old undergoing elective knee arthroplasty were prospectively evaluated for postoperative Diagnostic and Statistical Manual of Mental Disorders-IV delirium. Exclusion criteria included dementia, mini-mental state exam score $<24$, delirium, clinically significant CNS/neurological disorder, current alcoholism, or any serious psychiatric disorder. Delirium was assessed on postoperative days 2 and 3 using standardized scales. Patients' preexisting medical conditions were obtained from medical charts. The occurrence of obstructive sleep apnea (OSA) was confirmed by contacting patients to check their polysomnography records. Data were analyzed using Pearson Chi-Square or Wilcoxon Rank Sum tests and multiple logistic regressions adjusted for effects of covariates.

Results-Of 106 enrolled patients, 27 (25\%) developed postoperative delirium. Of the 15 patients with obstructive sleep apnea, 8 (53\%) experienced postoperative delirium, compared to 19 (20\%) of the patients without obstructive sleep apnea ( $\mathrm{p}=0.0123$, OR: 4.3). Obstructive sleep apnea was the only statistically significant predictor of postoperative delirium in multivariate analyses.

Conclusions-This is the first prospective study employing validated measures of delirium to identify an association between pre-existing obstructive sleep apnea and postoperative delirium.

\section{INTRODUCTION}

Postoperative delirium (POD), a common complication in the elderly, is associated with increased morbidity and mortality 1,2 and has recently been associated with long-term cognitive and functional decline. ${ }^{3,4}$ Effective therapies for postoperative delirium remain elusive because we do not understand the biology of delirium. ${ }^{5}$ Recent data indicate that the incidence of POD in elderly patients undergoing major surgeries is quite variable, ranging from $5-15 \%$ in patients undergoing general anesthesia ${ }^{6}$ to as high as $62 \%$ in hip fracture patients ${ }^{7}$ and $73 \%$ in elderly cardiac surgery patients. ${ }^{8}$ In surgeries requiring postoperative intensive care, the incidence of POD was found to be $44 \% .{ }^{9}$ Finally, in the case of elective orthopedic surgery, a recent study reports an incidence of $22 \%$ in hip replacement patients and $32 \%$ in knee replacement patients. ${ }^{10}$

Given the high incidence and clinically significant sequelae of POD in the elderly, it is crucial to better understand the risk factors for and pathophysiology of delirium. Studies have identified several clinical risk factors for POD, including preexisting subtle cognitive impairment, dementia, low mini-mental state exam (MMSE) score, active depressive symptoms, preoperative psychotropic drug use, alcohol abuse, functional impairment, and intraoperative procedural issues such as oxygen desaturation. ${ }^{11-15}$

Total knee arthroplasty (TKA) is a routine procedure in the elderly population and has been shown to restore functional status and improve patient pain. ${ }^{16,17}$ While TKA does increase the risk of morbidity and mortality, there is strong evidence to support its use in elderly patients ${ }^{18-20}$, and recent changes in treatment strategies have improved the safety of the procedure ${ }^{16}$ In patients undergoing TKA in the United States, osteoarthritis is present $95 \%$ 
of the time. ${ }^{21}$ Patients tend to be female (62\%) and obese (56\%), with an average body mass index (BMI) of 31; their average age is $69 .{ }^{21}$ Knee arthroplasty was chosen as a procedure for our study based on the volume of patients seen at our institution, the average age of patients undergoing surgery, and the elective nature of the procedure, allowing for the examination of a delirium in a healthy elderly population.

The present study was undertaken to explore the molecular markers of POD by prospectively recruiting a cohort of elderly patients undergoing elective knee replacement surgery. While our molecular studies are ongoing, we examined whether any of the preexisting medical conditions found in our patients contribute to POD. We report here that in elderly patients undergoing elective knee replacement surgery, there is an association between pre-existing OSA and POD.

\section{MATERIALS AND METHODS}

\section{Subjects}

After obtaining approval from our Institutional Review Board (Duke University, Durham, $\mathrm{NC}$ ), we prospectively recruited 106 elderly persons aged $\geq 65$ scheduled to undergo elective single knee replacement surgery at Duke University Medical Center or the Durham Veterans Association Medical Center. Informed consent was obtained from all patients. Because we sought to examine the development of new-onset postoperative delirium, patients with pre-existing delirium were excluded. Other exclusion criteria included alcohol abuse or dependence within last 3 months, active psychosis within the last 3 months, current depression, dementia, MMSE $<24$, and/or clinically significant neurological disorder.

Approximately 400 total knee replacements per year were done in our hospital system during the study period. Of these, approximately 80 percent of the patients were over the age of 65 . This study included patients undergoing knee replacement surgery by any of three surgeons at our institution. The initial goal was to recruit enough patients so that we would have between 25 and 50 delirious patients, an empirical number needed for gene expression analysis; no a priori power calculation was conducted for the specific association with sleep apnea. Patient recruitment was based on the availability of our staff nurse. Of the 149 patients originally consented, 106 completed the study. 16 patients were excluded after consent was obtained: 6 patients cancelled their surgery, 7 patients refused blood work or otherwise did not complete the study, 4 were excluded because of alcohol abuse noted upon further evaluation, 2 patients died before their surgery date, and 7 patients were excluded for other reasons.

Subjects were recruited and evaluated by two study nurses who have training in psychiatry and received training in the study assessment methods. In cases where there were questions in terms of a patient's diagnosis or eligibility, the study psychiatrist adjudicated using all available information, including chart review. The study psychiatrist reviewed each chart, including all testing by the study nurses.

Dementia was evaluated in all patients by review of the medical record, administration of the MMSE, ${ }^{22}$ and structured interview questions to assess for any limitations in independent activities of daily living. Subjects with a diagnosis of dementia or a MMSE score less than 24 were excluded. MMSE scores were adjusted for age and education level. ${ }^{23}$ If the MMSE was 24 or more yet limitations in independent activities of daily living were noted, further questions to assess for dementia using Diagnostic and Statistical Manual of Mental Disorders, $4^{\text {th }}$ ed. (DSM-IV) $)^{24}$ criteria were used; patients meeting criteria for dementia were excluded. 
The CAGE questionnaire ${ }^{25}$ was used to screen for alcohol abuse; subjects with a score of $\geq$ 2 or with a history of active alcohol abuse or dependence were excluded. The Geriatric Depression Scale ${ }^{26}$ was used to evaluate patients for current depression, and subjects scoring 4 or greater were excluded. Patients with a documented or reported diagnosis of a psychiatric disorder and/or receiving psychiatric medications were included, provided they did not screen positive on the scales above nor meet the criteria for a current mood episode nor psychosis at or within three months of preoperative evaluation.

Patients were evaluated prior to surgery and on postoperative days 2 and 3 unless discharged prior to those time points. There were 3 subjects who were discharged prior to the postoperative day 3 assessment. Postoperative day 1 was not included in order to minimize the role of residual anesthesia effects. Observations were limited to postoperative days 2 and 3 because the vast majority of patients were discharged on postoperative day 3 , and prior studies have shown that most postoperative delirium occurs on postoperative days 2 and $3 .{ }^{27}$

Patients were screened for baseline delirium using the Confusion Assessment Method $(\mathrm{CAM})^{28}$ and the Delirium Rating Scale-Revised-98 (DRS-R98). The CAM is a four-item screening tool based on criteria for delirium from the DSM-III-R. The CAM requires the presence of acute onset and fluctuating course, inattention and either disorganized thinking or an altered level of consciousness to suggest a diagnosis of delirium. The 16-item DRSR98 is a delirium symptom rating scale with anchored severity ratings for a broad range of symptoms, which has been validated to discriminate between dementia and other neuropsychiatric conditions. ${ }^{29}$ The DRS-R98 provides a numerical value for delirium severity, with a 39-point maximum for the Severity score and a 46-point maximum for the Total score. Patients who screened positive for delirium by the CAM prior to surgery were excluded from the study. Subjects that had a baseline DRS score $>0$ were reviewed by the study psychiatrist; they were excluded from the study if they met DSM-IV criteria for delirium.

Assessments for delirium on postoperative days 2 and 3 were performed in the mornings, though not at a standard time. The period of inquiry for the DRS includes the 24 hours prior to the assessment, while the CAM is cross-sectional. Because the CAM is only a screening tool, it may only suggest a diagnosis of delirium, and cases may be missed at the time of assessment, particularly due to the fluctuating nature of delirium. Thus, delirium was diagnosed using the DSM IV criteria and all available data, including that from the CAM, DRS, and chart documentation (nursing, physical therapy, and physician notes), by the study psychiatrist. Specifically, charts were examined for evidence of: 1) disturbance of consciousness, with reduced ability to focus, sustain or shift attention; 2) change in cognition or the development of a new perceptual disturbance not accounted for by a preexisting, established or evolving dementia; 3 ) development of the disturbance over a short period of time (usually hours to days) and a tendency to fluctuate during the course of the day and 4) a likely medical etiology.

There were four subjects who had a negative screening for delirium by the CAM but DRS scores $>0$ on postoperative day 2 . These four subjects' charts were reviewed by the study psychiatrist and a diagnosis of delirium was made using DSM-IV criteria in each case. The mean DRS severity score for these subjects was 8.25 and the total severity score was 13.5. There was one subject on postoperative day 3 who screened negative for delirium by CAM at the time of the assessment, but had a DRS severity score of 17 and total score of 24 and met DSM-IV criteria for delirium in the past 24 hours.

Baseline medical diagnoses and pulse oximetry were obtained from the admission note and preoperative anesthesia evaluation. Any conditions occurring in at least $10 \%$ of cases were 
tested for association with POD. These were benign prostatic hyperplasia, coronary artery disease, diabetes, gastroesophageal reflux disorder, hypertension, hyperlipidemia, incontinence, and OSA. The presence of a major neurological disorder was determined through interview and review of the patient's medical records. Patients with neurological disorders with clinically significant sequelae that might interfere with assessment of delirium such as prior stroke or head trauma with deficits such as aphasia or agnosia were excluded. Patients with a history of transient ischemic attack without clinically significant sequelae were included.

\section{Procedures}

All patients underwent elective TKA or revision of a TKA. The choice of anesthesia was at the discretion of the anesthesiologist and included both general and regional anesthesia. Preoperative oxygen saturation and hemoglobin data were obtained from medical charts. BMI was calculated using weight and height data from pre-operative admission evaluation. Postoperative oxygen saturation data was not included due to the lack of continuous or standardized data collection.

Following their operations, patients were assessed for POD using the CAM and the DRSR98. The diagnosis of delirium was made by the study psychiatrist using the DSM-IV criteria, information gathered in the DRS-R98, CAM, and nursing notes. Patients were tested for delirium on postoperative day 2 and postoperative day 3 by study staff.

From medical records, 16 patients were initially identified as having OSA. In 15 of the 16 cases, verification of OSA was obtained. For 12 out of 15 patients, we were able to obtain polysomnography (PSG) reports. PSG reports were reviewed by one of our research team (AK), a board certified physician in sleep medicine, to confirm the presence of OSA. This review included the diagnostic criterion of the presence of 5 or more apneic events per hour as determined by PSG. ${ }^{30,31}$ For two of the three patients without PSG reports, the use of home continuous positive airway pressure (CPAP) was employed as a surrogate confirmation of OSA diagnosis. The third patient who did not have PSG records had undergone uvulopalatoplasty surgery 10 years earlier but had returned to his pre-surgical OSA symptoms at the time of his participation in our study, and the medical team ordered CPAP during his hospital stay. Given the possibility of uvulopalatoplasty failure ${ }^{32}$ and the return of baseline symptoms, this patient was coded as an OSA patient.

The home usage of CPAP by OSA patients was ascertained through preoperative anesthesia interviews. The use of CPAP administration in the hospital after the surgical procedure was determined using nursing records, physician orders and progress notes.

\section{Statistical Analysis}

Patients who did not develop delirium were compared with those who became delirious on postoperative day 2 and/or 3. Categorical variables were analyzed using 2-tailed Pearson Chi Square tests with exact tests for small cell counts. Continuous demographic variables were compared with Wilcoxon Rank Sum tests (2-sided independent sample tests). The effect of OSA on POD and their potential interactions were further assessed with separate logistic regression models adjusting for covariates. Covariates tested included age, sex, race (Caucasian vs. other), BMI, preoperative oxygen saturation, preoperative hemoglobin concentration, anesthesia type (general vs. other), MMSE, educational level, and baseline medical diagnoses. Due to the low incidence of delirium, only one covariate at a time could be tested reliably. Follow-up testing was performed to determine the effect of home and inhospital CPAP use on the development of POD. Statistical significance for all tests was determined as $\mathrm{p}<0.05$ without adjustment. Descriptive statistics are presented as mean \pm 
standard deviation (SD) for numeric measures and as count (Percent) for categorical variables. Statistical analysis was completed using SAS version 9.2, SAS Institute Inc., Cary, NC.

\section{RESULTS}

\section{Incidence and Characteristics of POD}

Twenty-seven of the 106 patients developed POD, for an incidence of $25.5 \%$ (95\% confidence interval $17.5 \%$ to $34.9 \%$ ). Twenty-four ( $89 \%$ of those with delirium) became delirious on postoperative day 2 , and 9 of these were delirious on both postoperative day 2 and postoperative day 3 ( $8.5 \%$ of all patients, $95 \%$ confidence interval $4.0 \%$ to $15.5 \%$ ). Mean postoperative DRS-R98 Total was $16 \pm 6$ and Severity was $11 \pm 5$ in the delirium group, as compared to DRS-R98 Total 3.7 \pm 3.6 and Severity $2.1 \pm 2.0$ in the nondelirium group. There was no statistically significant sex difference for delirium incidence (30\% of females vs. $19 \%$ of males, $\mathrm{p}=0.182$ ). There were no statistically significant differences between the delirium and nondelirium groups for age, race, education, baseline MMSE, BMI, preoperative oxygen saturation, American Society of Anesthesiologists score (Table 1). No difference was found between patients who received general vs. regional anesthesia $(\mathrm{p}=0.1750)$. A small amount of data was unavailable for some of the secondary analysis variables (17 data points were unavailable out of the 4,028 collected, $0.4 \%$ ).

\section{POD and Pre-existing Comorbidities}

The incidence of POD was higher in patients with OSA. Among patients with OSA, 53.3\% (8/15) experienced POD, compared with $20.9 \%$ of patients without OSA (19/91) (exact $\mathrm{p}=0.0123$, odds ratio $=4.3$, exact $95 \%$ confidence interval 1.2 to 15.8 ) (see Table 1 ). No statistically significant association was found between postoperative delirium and other baseline medical conditions, listed in table 1 . In the adjusted multiple logistic tests, OSA was consistently a statistically significant independent predictor of delirium (largest $\mathrm{p}=0.0237$ ), whereas none of the covariates or their interactions were significant. Also, although we found no difference between the delirium and nondelirium groups in presurgery oxygen saturation levels ( $\mathrm{p}=0.4173$ ), those who developed delirium had significantly lower mean preoperative hemoglobin levels compared to the nondelirium group (12.8 g/dL vs. $13.4 \mathrm{~g} / \mathrm{dL}, \mathrm{p}=0.0476$, see Table 1$)$. However, this difference did not hold up as being significant in multivariate analyses; only OSA remained a statistically significant predictor of delirium.

\section{POD and OSA}

Since OSA is associated with obesity and may lead to lower oxygen saturation, we examined whether BMI and preoperative oxygen saturation were associated with postoperative delirium. We found that the mean BMI of patients with OSA was $5.6 \mathrm{~kg} / \mathrm{m}^{2}$ higher than that of patients without OSA ( $\mathrm{p}=0.0047$ ) (Table 2), but we found no statistically significant association between postoperative delirium and BMI $(\mathrm{p}=0.5281)$. No difference was seen between patients with and without OSA in preoperative oxygen saturation $(\mathrm{p}=0.7648)$ or hemoglobin levels $(\mathrm{p}=0.3717)$. Table 2 compares the demographic profiles of 15 patients with OSA and 91 patients without OSA. In addition to developing POD more frequently, the OSA group was significantly younger $(70.3 \pm 3.3$ vs. $74 \pm 5.1, \mathrm{p}=0.0111)$ and had more medical co-morbidities $(3.9 \pm 2.5$ vs. $2.9 \pm 1.6, \mathrm{p}=0.0074)$.

We also examined the use of CPAP by OSA patients and the incidence of POD. As Table 3 shows, the home use of CPAP by OSA patients who became delirious (4/8) and who did not (4/7) was similar. However, the use of CPAP in hospital was higher in OSA patients who 
did not become delirious (4/7) than those who became delirious (2/8), but the difference in usage was not statistically significant in this small sample.

\section{DISCUSSION}

Using sensitive measures of delirium, our prospective study found a $25.5 \%$ incidence of POD in relatively healthy nondemented elderly patients undergoing elective knee replacement surgery. Interestingly, despite our stringent exclusion criteria, our study still found an incidence of POD which is comparable to that reported in recent studies that did not specifically exclude patients with dementia, which is a major risk factor for delirium in older persons. ${ }^{10,12,33}$ The most notable clinical finding of this study is the identification of a possible association between postoperative delirium and pre-existing OSA. Given the exploratory nature of our investigation, we present this finding as hypothesis-generating and recognize that a more definitive study of the association is needed.

POD was most frequent on postoperative day 2, consistent with previous reports. ${ }^{27,} 34$ The POD seen in our patient population was of mild severity as measured by the DRS-R98 scale. The majority (66\%) of patients who were delirious on postoperative day 2 had recovered by postoperative day 3 . We did not assess POD on postoperative day 4 because most of the patients had been discharged by that time.

Inadequate oxygenation is a well-known cause of delirium, and the impact of hemoglobin on the development of delirium has been reported in previous studies. ${ }^{35-40}$ Patients in our study who developed delirium had significantly lower preoperative hemoglobin levels than those who did not develop delirium, though this difference did not remain statistically significant in multivariate models. In fact, only OSA was significantly associated with POD in our study, but OSA has not been evaluated in other POD reports. The interplay between hemoglobin, OSA and delirium is less clear. In a study of delirium predictors in 101 intensive care unit patients, investigators found an association between lower premorbid hemoglobin levels and development of delirium. ${ }^{38}$ Anemia has also been shown to be an independent predictor of delirium in the acutely ill elderly population. ${ }^{36}$ Furthermore, several studies have shown an association between lower postoperative hemoglobin levels and POD in multiple surgery populations. ${ }^{35,37,39,40}$ One study of 44 intensive care unit patients failed to find an association between lower premorbid hemoglobin levels and delirium, but this study may have been underpowered. ${ }^{41}$

In our sample, OSA was associated with a more than 4-fold increased risk for incident POD and was the only baseline clinical factor associated with POD in multivariate models. While delirium occurred even in those who used their CPAP in the hospital, the use of CPAP appears to have benefit in OSA patients, though our numbers are small and deserve replication in a larger sample. Although an association between OSA and POD has been identified in a case report ${ }^{42}$ and a prior retrospective study, ${ }^{43}$ this is, to our knowledge, the first prospective study employing validated measures of POD that identifies OSA as a potential risk factor for POD. In fact, previous studies examining multiple risk factors for POD have not evaluated the potential impact of preexisting OSA. ${ }^{9,11-13}$

An association of OSA and POD represents a significant public health problem given the prevalence and under-diagnosis of OSA, particularly in the elderly, and its frequent misdiagnosis as insomnia. OSA is highly prevalent in the adult population and is estimated to affect 3.9-4\% of men and 1.2-2\% of women in the United States, ${ }^{44-46}$ rising to over $20 \%$ of the population over the age of $65 .{ }^{47}$ Furthermore, it has been estimated that about $80 \%$ of men and $93 \%$ of women with moderate to severe OSA are undiagnosed. ${ }^{48,49}$ In the surgical population, a recent prospective study using portable sleep testing found that $82 \%$ of a group 
of previously undiagnosed surgical patients who screened as high risk for OSA in fact had the diagnosis. ${ }^{50}$ Thus, the results of this study suggest that a large number of patients undergoing surgery appear to be at risk for both POD and the associated adverse consequences of undetected OSA.

Our study provides preliminary evidence to support better pre-surgical screening for OSA and institution of effective therapy for OSA as means to reduce this risk. This is consistent with recent recommendations to screen for and treat OSA in order to decrease adverse perioperative respiratory and cardiovascular outcomes associated with OSA. ${ }^{51}$ Further studies will be needed to identify whether CPAP, the mainstay of OSA therapy, or other available OSA treatments mitigate the risks for POD associated with OSA. We found a preliminary trend suggesting a decreased chance of delirium among CPAP-treated patients, consistent with case reports in which delirium was resolved using positive airway pressure for both OSA and central sleep apnea. ${ }^{52-54}$

The mechanism by which OSA increases the risk for POD remains unknown, though there is reason to believe that the reduced oxygen metabolism that occurs with OSA might be playing a role. OSA is a sleep disorder characterized by the recurrent collapse of the pharynx, causing upper airway obstruction and leading to recurrent arousals during sleep and episodes of oxygen desaturation, ${ }^{31,55}$ and hypoxia is a known cause of delirium. ${ }^{56}$ Consistent with this etiology, a previous study reported that all of its enrolled patients who became delirious after thoracotomy for pulmonary malignancy had inadequate arterial oxygen saturation; delirium in these patients was resolved by administration of supplemental oxygen. ${ }^{57}$ However, oxygen desaturation has not been consistently shown to predict the development of delirium in either the medical or the postoperative setting ${ }^{38,58}$ and in our study, no association was found between preoperative oxygen saturation levels and POD or OSA. Further, one study found that infrared spectroscopy measurement of prefrontal cortex oxygen desaturation during coronary artery bypass graft surgery predicted POD even when peripheral oxygen desaturation was not noted, ${ }^{15}$ suggesting that transient brain oxygenation deficits are important and may not be reflected with conventional monitoring methods.

It is also possible that hypoxemia may have occurred postoperatively. Given that mitochondrial defects consistent with oxidative stress are common with increased age, ${ }^{59}$ chronic nocturnal oxygen desaturation associated with OSA could conceivably exacerbate delirium risk by reducing adenosine triphosphate and synthesis of acetylcholine precursors (and hence cholinergic function). ${ }^{60-62}$ Extensive research supports a hypocholinergic state underlying delirium. ${ }^{6,63}$ Although all patients in this study underwent routine spot checking of their oxygen saturation, saturation was not recorded continuously, and we cannot exclude the possibility that OSA patients may have experienced periods of desaturation.

Other possible mechanisms linking OSA and delirium might include an increase in proinflammatory cytokines caused by OSA or by subacute or chronic oxidative stress. ${ }^{64,} 65$ The increase in inflammatory cytokines is thought to be related to repeated cycles of apneic oxygen desaturation and restoration. ${ }^{44,66-70}$ OSA has been shown to be an inflammatory process, associated with increased levels of systemic interleukin-2, interleukin-6, C-reactive protein, and tumor necrosis factor-alpha ${ }^{66,67,69,71-74}$ There is a growing body of literature supporting the role of inflammatory cytokines in delirium, yet there is no consensus at this time. ${ }^{7,75-82}$

Future prospective studies that employ polysomnography and measure the impact of CPAP therapy are needed to confirm the OSA-POD association and establish the mechanism by which OSA might increase the risk of POD. A limitation of our research is the possible role of undiagnosed OSA. However, such false negatives would tend to dampen the observed 
effect of OSA that we found, so it is possible that the effect of OSA on POD is actually more substantial than our data indicate. Whether OSA is a risk factor for POD in patients undergoing other types of surgeries, such as coronary artery bypass graft, deserves study.

In summary, using multivariate regression, we identified preexisting OSA as the predominant predictive risk factor for incident postoperative delirium in elderly patients undergoing elective knee arthroplasty. A key limitation of our study is the small number of patients with OSA and the small number of patients with delirium. As with any observational finding, the importance of OSA in precipitating delirium needs rigorous examination in a hypothesis-directed study using a larger number of patients. Another limitation of our study is that a relationship between OSA and POD is confounded by the fact that our patients with OSA had significantly more co-morbidities that could increase the risk for POD in OSA patients. In our study, OSA patients had a higher likelihood of having diabetes, hypertension, hyperlipidemia, coronary artery disease, and obesity but we did not find a relationship between these individual conditions and POD. Future studies may be able to further characterize the relationship between various co-morbidities and POD in the OSA population. Another weakness of our study is that we did not collect information on certain predisposing factors, such as history of stroke, and precipitating factors, such as electrolyte disturbances, known to be associated with delirium, and omission of these risk factors might confound our findings. ${ }^{83}$

\section{Acknowledgments}

We thank Harvey Cohen, M.D. and Dr. Anthony Galanos, M.D. (Professors, Department of Medicine, Duke University, Durham, NC) for helpful discussions. We would also like to thank Kristine Brown for her help with data analysis and manuscript preparation.

Funding: National Institutes of Health grant R01-AG019766, Bethesda, MD, USA and Duke University Medical Center Department of Anesthesia, Durham, NC, USA.

\section{REFERENCES}

1. Young J, Inouye SK. Delirium in older people. BMJ. 2007; 334:842-6. [PubMed: 17446616]

2. Amador LF, Goodwin JS. Postoperative delirium in the older patient. J Am Coll Surg. 2005; 200:767-73. [PubMed: 15848371]

3. Rudolph JL, Inouye SK, Jones RN, Yang FM, Fong TG, Levkoff SE, Marcantonio ER. Delirium: An Independent Predictor of Functional Decline After Cardiac Surgery. J Am Geriatr Soc. 2010; 58:643-9. [PubMed: 20345866]

4. MacLullich AM, Beaglehole A, Hall RJ, Meagher DJ. Delirium and long-term cognitive impairment. Int Rev Psychiatry. 2009; 21:30-42. [PubMed: 19219711]

5. Mantz J, Hemmings HC Jr. Boddaert J. Case scenario: Postoperative delirium in elderly surgical patients. Anesthesiology. 2010; 112:189-95. [PubMed: 19996957]

6. Bekker AY, Weeks EJ. Cognitive function after anaesthesia in the elderly. Best Pract Res Clin Anaesthesiol. 2003; 17:259-72. [PubMed: 12817919]

7. Bitsch M, Foss N, Kristensen B, Kehlet H. Pathogenesis of and management strategies for postoperative delirium after hip fracture: A review. Acta Orthop Scand. 2004; 75:378-89. [PubMed: 15370579]

8. Sockalingam S, Parekh N, Israel Bogoch I, Sun J, Mahtani R, Beach C, Bollegalla N, Turzanski S, Seto E, Kim J, Dulay P, Scarrow S, Bhalerao S. Delirium in the Postoperative Cardiac Patient: A Review. J Card Surg. 2005; 20:560-7. [PubMed: 16309412]

9. Robinson TN, Raeburn CD, Tran ZV, Angles EM, Brenner LA, Moss M. Postoperative delirium in the elderly: Risk factors and outcomes. Ann Surg. 2009; 249:173-8. [PubMed: 19106695]

10. Contin AM, Perez-Jara J, Alonso-Contin A, Enguix A, Ramos F. Postoperative delirium after elective orthopedic surgery. Int J Geriatr Psychiatry. 2005; 20:595-7. [PubMed: 15962354] 
11. Rudolph JL, Jones RN, Levkoff SE, Rockett C, Inouye SK, Sellke FW, Khuri SF, Lipsitz LA, Ramlawi B, Levitsky S, Marcantonio ER. Derivation and validation of a preoperative prediction rule for delirium after cardiac surgery. Circulation. 2009; 119:229-36. [PubMed: 19118253]

12. Dasgupta M, Dumbrell AC. Preoperative risk assessment for delirium after noncardiac surgery: A systematic review. J Am Geriatr Soc. 2006; 54:1578-89. [PubMed: 17038078]

13. Afonso A, Scurlock C, Reich D, Raikhelkar J, Hossain S, Bodian C, Krol M, Flynn B. Predictive model for postoperative delirium in cardiac surgical patients. Semin Cardiothorac Vasc Anesth. 2010; 14:212-7. [PubMed: 20647262]

14. Noimark D. Predicting the onset of delirium in the post-operative patient. Age Ageing. 2009; 38:368-73. [PubMed: 19297372]

15. Slater JP, Guarino T, Stack J, Vinod K, Bustami RT, Brown JM 3rd, Rodriguez AL, Magovern CJ, Zaubler T, Freundlich K, Parr GV. Cerebral oxygen desaturation predicts cognitive decline and longer hospital stay after cardiac surgery. Ann Thorac Surg. 2009; 87:36-44. [PubMed: 19101265]

16. Talmo CT, Robbins CE, Bono JV. Total joint replacement in the elderly patient. Clin Geriatr Med. 2010; 26:517-29. [PubMed: 20699169]

17. Ethgen O, Bruyere O, Richy F, Dardennes C, Reginster JY. Health-related quality of life in total hip and total knee arthroplasty: A qualitative and systematic review of the literature. J Bone Joint Surg Am. 2004; 86-A:963-74. [PubMed: 15118039]

18. Jones CA, Voaklander DC, Johnston DW, Suarez-Almazor ME. The effect of age on pain, function, and quality of life after total hip and knee arthroplasty. Arch Intern Med. 2001; 161:45460. [PubMed: 11176772]

19. Hamel MB, Toth M, Legedza A, Rosen MP. Joint replacement surgery in elderly patients with severe osteoarthritis of the hip or knee: Decision making, postoperative recovery, and clinical outcomes. Arch Intern Med. 2008; 168:1430-40. [PubMed: 18625924]

20. Shah AK, Celestin J, Parks ML, Levy RN. Long-term results of total joint arthroplasty in elderly patients who are frail. Clin Orthop Relat Res. 2004:106-9. [PubMed: 15292795]

21. Waddell J, Johnson K, Hein W, Raabe J, FitzGerald G, Turibio F. Orthopaedic practice in total hip arthroplasty and total knee arthroplasty: Results from the Global Orthopaedic Registry (GLORY). Am J Orthop (Belle Mead NJ). 2010; 39:5-13. [PubMed: 21290026]

22. Folstein MF, Folstein SE, McHugh PR. "Mini-mental state": A practical method for grading the cognitive state of patients for the clinician. J Psychiatr Res. 1975; 12:189-98. [PubMed: 1202204]

23. Crum RM, Anthony JC, Bassett SS, Folstein MF. Population-based norms for the Mini-Mental State Examination by age and educational level. JAMA. 1993; 269:2386-91. [PubMed: 8479064]

24. Diagnostic and Statistical Manual of Mental Disorders. 4th ed. American Psychiatric Association; Washington, DC: 1994.

25. Buchsbaum DG, Buchanan RG, Welsh J, Centor RM, Schnoll SH. Screening for drinking disorders in the elderly using the CAGE questionnaire. J Am Geriatr Soc. 1992; 40:662-5. [PubMed: 1607581]

26. Yesavage JA, Sheikh JI. Geriatric Depression Scale (GDS): Recent evidence and development of a shorter violence. Clinical Gerontologist. 1986; 5:165-73.

27. Marcantonio ER, Goldman L, Mangione CM, Ludwig LE, Muraca B, Haslauer CM, Donaldson MC, Whittemore AD, Sugarbaker DJ, Poss R, Haas S, Cook EF, Orav EJ, Lee TH. A clinical prediction rule for delirium after elective noncardiac surgery. JAMA. 1994; 271:134-9. [PubMed: 8264068]

28. Inouye SK, van Dyck CH, Alessi CA, Balkin S, Siegal AP, Horwitz RI. Clarifying confusion: The confusion assessment method. A new method for detection of delirium. Ann Intern Med. 1990; 113:941-8. [PubMed: 2240918]

29. Trzepacz PT, Mittal D, Torres R, Kanary K, Norton J, Jimerson N. Validation of the Delirium Rating Scale-revised-98: Comparison with the delirium rating scale and the cognitive test for delirium. J Neuropsychiatry Clin Neurosci. 2001; 13:229-42. [PubMed: 11449030]

30. Jafari B, Mohsenin V. Polysomnography. Clin Chest Med. 2010; 31:287-97. [PubMed: 20488287]

31. Patil SP, Schneider H, Schwartz AR, Smith PL. Adult obstructive sleep apnea. Chest. 2007; 132:325-37. [PubMed: 17625094] 
32. Sundaram S, Bridgman SA, Lim J, Lasserson TJ. Surgery for obstructive sleep apnoea. Cochrane Database Syst Rev. 2005:CD001004. [PubMed: 16235277]

33. Kudoh A, Takase H, Takahira Y, Takazawa T. Postoperative confusion increases in elderly longterm benzodiazepine users. Anesth Analg. 2004; 99:1674-8. [PubMed: 15562052]

34. Lynch EP, Lazor MA, Gellis JE, Orav J, Goldman L, Marcantonio ER. The impact of postoperative pain on the development of postoperative delirium. Anesth Analg. 1998; 86:781-5. [PubMed: 9539601]

35. Gao R, Yang Z-z, Li M, Shi Z-c, Fu Q. Probable risk factors for postoperative delirium in patients undergoing spinal surgery. E Spine J. 2008; 17:1531-7.

36. Joosten E, Lemiengre J, Nelis T, Verbeke G, Milisen K. Is anaemia a risk factor for delirium in an acute geriatric population? Gerontology. 2006; 52:382-5. [PubMed: 16914932]

37. Marcantonio ER, Goldman L, Orav EJ, Cook EF, Lee TH. The association of intraoperative factors with the development of postoperative delirium. Am J Med. 1998; 105:380-4. [PubMed: 9831421]

38. Seaman JS, Schillerstrom J, Carroll D, Brown TM. Impaired oxidative metabolism precipitates delirium: A study of 101 ICU patients. Psychosomatics. 2006; 47:56-61. [PubMed: 16384808]

39. Shiiba M, Takei M, Nakatsuru M, Bukawa H, Yokoe H, Uzawa K, Tanzawa H. Clinical observations of postoperative delirium after surgery for oral carcinoma. Int J Oral Maxillofac Surg. 2009; 38:661-5. [PubMed: 19237264]

40. Wang SG, Lee UJ, Goh EK, Chon KM. Factors associated with postoperative delirium after major head and neck surgery. Ann Otol Rhinol Laryngol. 2004; 113:48-51. [PubMed: 14763573]

41. Watts G, Roberts BL, Parsons R. Delirium in the intensive care unit: Searching for causes and sources. Crit Care Resusc. 2007; 9:26-9. [PubMed: 17352663]

42. Lee JW. Recurrent delirium associated with obstructive sleep apnea. Gen Hosp Psychiatry. 1998; 20:120-2. [PubMed: 9582598]

43. Gupta RM, Parvizi J, Hanssen AD, Gay PC. Postoperative complications in patients with obstructive sleep apnea syndrome undergoing hip or knee replacement: A case-control study. Mayo Clin Proc. 2001; 76:897-905. [PubMed: 11560300]

44. Young T, Palta M, Dempsey J, Skatrud J, Weber S, Badr S. The occurrence of sleep-disordered breathing among middle-aged adults. N Engl J Med. 1993; 328:1230-5. [PubMed: 8464434]

45. Bixler EO, Vgontzas AN, Lin HM, Ten Have T, Rein J, Vela-Bueno A, Kales A. Prevalence of sleep-disordered breathing in women: effects of gender. Am J Respir Crit Care Med. 2001; 163:608-13. [PubMed: 11254512]

46. Kapur VK. Obstructive sleep apnea: Diagnosis, epidemiology, and economics. Respir Care. 2010; 55:1155-67. [PubMed: 20799998]

47. Young T, Peppard PE, Gottlieb DJ. Epidemiology of obstructive sleep apnea: A population health perspective. Am J Respir Crit Care Med. 2002; 165:1217-39. [PubMed: 11991871]

48. Young T, Evans L, Finn L, Palta M. Estimation of the clinically diagnosed proportion of sleep apnea syndrome in middle-aged men and women. Sleep. 1997; 20:705-6. [PubMed: 9406321]

49. Chung F, Yegneswaran B, Liao P, Chung SA, Vairavanathan S, Islam S, Khajehdehi A, Shapiro CM. STOP questionnaire: A tool to screen patients for obstructive sleep apnea. Anesthesiology. 2008; 108:812-21. [PubMed: 18431116]

50. Finkel KJ, Searleman AC, Tymkew H, Tanaka CY, Saager L, Safer-Zadeh E, Bottros M, Selvidge JA, Jacobsohn E, Pulley D, Duntley S, Becker C, Avidan MS. Prevalence of undiagnosed obstructive sleep apnea among adult surgical patients in an academic medical center. Sleep Med. 2009; 10:753-8. [PubMed: 19186102]

51. Adesanya AO, Lee W, Greilich NB, Joshi GP. Perioperative management of obstructive sleep apnea. Chest. 2010; 138:1489-98. [PubMed: 21138886]

52. Whitney JF, Gannon DE. Obstructive sleep apnea presenting as acute delirium. Am J Emerg Med. 1996; 14:270-1. [PubMed: 8639200]

53. Munoz X, Marti S, Sumalla J, Bosch J, Sampol G. Acute delirium as a manifestation of obstructive sleep apnea syndrome. Am J Respir Crit Care Med. 1998; 158:1306-7. [PubMed: 9769297]

54. Becker K, Poon C, Zeidler M, Wang T. An unusual cause of delirium. J Clin Sleep Med. 2010; 6:290-1. [PubMed: 20572424] 
55. Isono S. Obstructive sleep apnea of obese adults: Pathophysiology and perioperative airway management. Anesthesiology. 2009; 110:908-21. [PubMed: 19293689]

56. Winawer N. Postoperative delirium. Med Clin North Am. 2001; 85:1229-39. [PubMed: 11565496]

57. Aakerlund LP, Rosenberg J. Postoperative delirium: Treatment with supplementary oxygen. Br J Anaesth. 1994; 72:286-90. [PubMed: 8130045]

58. Eikermann M, Garzon-Serrano J, Kwo J, Grosse-Sundrup M, Schmidt U, Bigatello L. Do patients with obstructive sleep apnea have an increased risk of desaturation during induction of anesthesia for weight loss surgery? Open Respir Med J. 2010; 4:58-62. [PubMed: 20802806]

59. Wallace DC. A mitochondrial paradigm of metabolic and degenerative diseases, aging, and cancer: A dawn for evolutionary medicine. Annu Rev Genet. 2005; 39:359-407. [PubMed: 16285865]

60. Hossmann KA. Viability thresholds and the penumbra of focal ischemia. Ann Neurol. 1994; 36:557-65. [PubMed: 7944288]

61. Ksiezak HJ, Gibson GE. Oxygen dependence of glucose and acetylcholine metabolism in slices and synaptosomes from rat brain. J Neurochem. 1981; 37:305-14. [PubMed: 7264662]

62. Kurth CD, Levy WJ, McCann J. Near-infrared spectroscopy cerebral oxygen saturation thresholds for hypoxia-ischemia in piglets. J Cereb Blood Flow Metab. 2002; 22:335-41. [PubMed: 11891439]

63. Trzepacz PT. Is there a final common neural pathway in delirium? Focus on acetylcholine and dopamine. Semin Clin Neuropsychiatry. 2000; 5:132-48. [PubMed: 10837102]

64. Pialoux V, Hanly PJ, Foster GE, Brugniaux JV, Beaudin AE, Hartmann SE, Pun M, Duggan CT, Poulin MJ. Effects of exposure to intermittent hypoxia on oxidative stress and acute hypoxic ventilatory response in humans. Am J Respir Crit Care Med. 2009; 180:1002-9. [PubMed: 19713446]

65. Arnardottir ES, Mackiewicz M, Gislason T, Teff KL, Pack AI. Molecular signatures of obstructive sleep apnea in adults: A review and perspective. Sleep. 2009; 32:447-70. [PubMed: 19413140]

66. Dyugovskaya L, Lavie P, Lavie L. Increased adhesion molecules expression and production of reactive oxygen species in leukocytes of sleep apnea patients. Am J Respir Crit Care Med. 2002; 165:934-9. [PubMed: 11934717]

67. Khan A, Ashizawa S, Hlebowicz V, Appel D. Anemia of aging and obstructive sleep apnea. Sleep Breath. 2011; 15:29-34. [PubMed: 20162370]

68. McGown AD, Makker H, Elwell C, Al Rawi PG, Valipour A, Spiro SG. Measurement of changes in cytochrome oxidase redox state during obstructive sleep apnea using near-infrared spectroscopy. Sleep. 2003; 26:710-6. [PubMed: 14572124]

69. Schulz R, Mahmoudi S, Hattar K, Sibelius U, Olschewski H, Mayer K, Seeger W, Grimminger F. Enhanced release of superoxide from polymorphonuclear neutrophils in obstructive sleep apnea: Impact of continuous positive airway pressure therapy. Am J Respir Crit Care Med. 2000; 162:566-70. [PubMed: 10934088]

70. Wolk R, Somers VK. Cardiovascular consequences of obstructive sleep apnea. Clin Chest Med. 2003; 24:195-205. [PubMed: 12800778]

71. Entzian P, Linnemann K, Schlaak M, Zabel P. Obstructive sleep apnea syndrome and circadian rhythms of hormones and cytokines. Am J Respir Crit Care Med. 1996; 153:1080-6. [PubMed: 8630548]

72. Hui Y, Funk CD. Cysteinyl leukotriene receptors. Biochem Pharmacol. 2002; 64:1549-57. [PubMed: 12429344]

73. Vgontzas AN, Papanicolaou DA, Bixler EO, Hopper K, Lotsikas A, Lin HM, Kales A, Chrousos GP. Sleep apnea and daytime sleepiness and fatigue: Relation to visceral obesity, insulin resistance, and hypercytokinemia. J Clin Endocrinol Metab. 2000; 85:1151-8. [PubMed: 10720054]

74. Vgontzas AN, Papanicolaou DA, Bixler EO, Kales A, Tyson K, Chrousos GP. Elevation of plasma cytokines in disorders of excessive daytime sleepiness: Role of sleep disturbance and obesity. $\mathrm{J}$ Clin Endocrinol Metab. 1997; 82:1313-6. [PubMed: 9141509]

75. Cerejeira J, Firmino H, Vaz-Serra A, Mukaetova-Ladinska E. The neuroinflammatory hypothesis of delirium. Acta Neuropathologica. 2010; 119:737-54. [PubMed: 20309566] 
76. Adamis D, Lunn M, Martin FC, Treloar A, Gregson N, Hamilton G, Macdonald AJ. Cytokines and IGF-I in delirious and non-delirious acutely ill older medical inpatients. Age Ageing. 2009; 38:326-32. [PubMed: 19269948]

77. Adamis D, Treloar A, Martin FC, Gregson N, Hamilton G, Macdonald AJ. APOE and cytokines as biological markers for recovery of prevalent delirium in elderly medical inpatients. Int J Geriatr Psychiatry. 2007; 22:688-94. [PubMed: 17203511]

78. Parikh SS, Chung F. Postoperative delirium in the elderly. Anesth Analg. 1995; 80:1223-32. [PubMed: 7762856]

79. Silverstein JH, Timberger M, Reich DL, Uysal S. Central nervous system dysfunction after noncardiac surgery and anesthesia in the elderly. Anesthesiology. 2007; 106:622-8. [PubMed: 17325520]

80. Rudolph JL, Ramlawi B, Kuchel GA, McElhaney JE, Xie D, Sellke FW, Khabbaz K, Levkoff SE, Marcantonio ER. Chemokines are associated with delirium after cardiac surgery. J Gerontol A Biol Sci Med Sci. 2008; 63:184-9. [PubMed: 18314455]

81. van Munster BC, Bisschop PH, Zwinderman AH, Korevaar JC, Endert E, Wiersinga WJ, Oosten HEv, Goslings JC, de Rooij SE. Cortisol, interleukins and S100B in delirium in the elderly. Brain Cogn. 2010; 74:18-23. [PubMed: 20580479]

82. Plaschke K, Fichtenkamm P, Schramm C, Hauth S, Martin E, Verch M, Karck M, Kopitz J. Early postoperative delirium after open-heart cardiac surgery is associated with decreased bispectral EEG and increased cortisol and interleukin-6. Intensive Care Med. 2010; 36:2081-9. [PubMed: 20689917]

83. Marcantonio ER. In the clinic: Delirium. Ann Intern Med. 2011; 154:1-16. [PubMed: 21041570] 
Brief Summary Statement: This is the first prospective study employing validated measures of delirium to identify an association between pre-existing obstructive sleep apnea and postoperative delirium. 


\section{MS \#201106064 - Final Boxed Summary}

What We Already Know about This Topic

* The causes of postoperative delirium are not yet known.

What This Article Tells Us That Is New

* In a small group of patients undergoing total knee replacement, postoperative delirium was associated with sleep apnea.

* Because the study is limited, further evaluation is needed; nevertheless, the association of postoperative delirium and sleep apnea if verified will be of significant clinical importance. 
Table 1

Clinical Characteristics of Knee Arthroplasty Patients

\begin{tabular}{|c|c|c|c|}
\hline Characteristic & $\begin{array}{l}\text { Nondelirious } \\
(\mathbf{N}=79)\end{array}$ & $\begin{array}{l}\text { Delirious } \\
(\mathbf{N}=27)\end{array}$ & p-Value ${ }^{*}$ \\
\hline Age \pm SD & $73.7 \pm 5.1$ & $72.9 \pm 4.9$ & 0.4832 \\
\hline Female Sex, n (\%) & $41(51.9)$ & $18(66.7)$ & 0.1824 \\
\hline Caucasian, n (\%) & $73(92.4)$ & $23(85.2)$ & 0.2679 \\
\hline $\operatorname{ASA}^{1}$ Score $=3(\operatorname{vs} 2), \mathrm{n}(\%)$ & $48(60.8)$ & $15(55.6)$ & 0.6345 \\
\hline $\operatorname{MMSE}^{5} \pm \mathrm{SD}$ & $29.2 \pm 1.4$ & $29.1 \pm 1.1$ & 0.2601 \\
\hline Education (years) \pm SD & $14.9 \pm 3.2$ & $14.5 \pm 3$ & 0.6194 \\
\hline Received General Anesthesia, n (\%) & $32(40.5)$ & $7(25.9)$ & 0.1750 \\
\hline Procedure on Left Knee, n (\%) & $43(54.4)$ & $13(48.1)$ & 0.5724 \\
\hline TKA $^{7}$ Revision Procedure, $n(\%)$ & $7(8.9)$ & $1(3.7)$ & 0.3812 \\
\hline Body Mass Index \pm SD & $31.1 \pm 7.3$ & $31.9 \pm 7.2$ & 0.5281 \\
\hline Preop Hemoglobin $(\mathrm{g} / \mathrm{dl}) \pm \mathrm{SD}$ & $13.4 \pm 0.2$ & $12.8 \pm 0.3$ & 0.0476 \\
\hline Preop Oxygen Saturation \pm SD & $96.9 \pm 1.6$ & $97 \pm 1.6$ & 0.4173 \\
\hline Number of Preop Comorbidities \pm SD & $3 \pm 1.7$ & $3.1 \pm 1.4$ & 0.5424 \\
\hline Coronary Artery Disease, n (\%) & $12(15.2)$ & $6(22.2)$ & 0.4008 \\
\hline Diabetes, n (\%) & $9(11.4)$ & $5(18.5)$ & 0.3451 \\
\hline Hypertension, n (\%) & $58(73.4)$ & $23(85.2)$ & 0.2137 \\
\hline Hyperlipidemia, n (\%) & $35(44.3)$ & $12(44.4)$ & 0.9899 \\
\hline Sleep Apnea, n (\%) & $7(8.9)$ & $8(29.6)$ & 0.0123 \\
\hline $\mathrm{BPH}^{2}, \mathrm{n}(\%)$ & $15(19)$ & $2(7.4)$ & 0.15699 \\
\hline Incontinence, $\mathbf{n}(\%)$ & $9(11.4)$ & $6(22.2)$ & 0.1634 \\
\hline GERD $^{4}, \mathrm{n}(\%)$ & $26(32.9)$ & $11(40.7)$ & 0.4612 \\
\hline Higher DRS-R98 ${ }^{3}$ Total, POD $^{6} 2,3 \pm$ SD & $3.7 \pm 3.6$ & $16.1 \pm 5.6$ & $<.0001$ \\
\hline Higher DRS-R98 Severity Score, POD2,3 \pm SD & $2.1 \pm 2$ & $10.7 \pm 5$ & $<.0001$ \\
\hline \multicolumn{4}{|c|}{ p-value from Pearson chi-square or Wilcoxon Rank Sum test of association between comorbidity and any postoperative deliriur } \\
\hline \multicolumn{4}{|l|}{ American Society of Anesthesiologists } \\
\hline \multicolumn{4}{|l|}{ Benign prostatic hyperplasia } \\
\hline \multicolumn{4}{|l|}{ Delirium Rating Scale-Revised-98 } \\
\hline \multicolumn{4}{|l|}{ Gastroesophageal reflux disorder } \\
\hline \multicolumn{4}{|l|}{ Mini-mental state examination } \\
\hline \multicolumn{4}{|l|}{ Postoperative Day } \\
\hline
\end{tabular}


Table 2

Clinical Characteristics of Knee Arthroplasty Patients with and without Sleep Apnea

\begin{tabular}{|c|c|c|c|}
\hline Characteristic & $\begin{array}{l}\text { No Sleep Apnea } \\
(\mathrm{N}=91)\end{array}$ & $\begin{array}{l}\text { Sleep Apnea } \\
(\mathrm{N}=15)\end{array}$ & p-Value ${ }^{*}$ \\
\hline Age \pm SD & $74 \pm 5.1$ & $70.3 \pm 3.3$ & 0.0111 \\
\hline Female Sex, n (\%) & $52(57.1)$ & $7(46.7)$ & 0.5768 \\
\hline Caucasian, n (\%) & $83(91.2)$ & $13(88.7)$ & 0.6309 \\
\hline ASA $^{1}$ Score=3 (vs 2), n (\%) & $52(57.1)$ & $11(73.3)$ & 0.2715 \\
\hline $\mathrm{MMSE}^{4} \pm \mathrm{SD}$ & $29.1 \pm 1.4$ & $29.4 \pm 0.8$ & 0.5244 \\
\hline Education (years) \pm SD & $14.8 \pm 3.2$ & $14.9 \pm 2.5$ & 0.7717 \\
\hline Received General Anesthesia, n (\%) & $33(36.2)$ & $6(40)$ & 0.9999 \\
\hline Procedure on Left Knee, n (\%) & $46(50.6)$ & $10(66.7)$ & 0.2780 \\
\hline TKA $^{5}$ Revision Procedure, $n(\%)$ & $6(6.6)$ & $2(13.3)$ & 0.3156 \\
\hline Body Mass Index $\left(\mathrm{Kg} / \mathrm{M}^{2}\right) \pm \mathrm{SD}$ & $30.5 \pm 6.8$ & $36.1 \pm 7.9$ & 0.0047 \\
\hline Preop Hemoglobin $(\mathrm{g} / \mathrm{dl}) \pm \mathrm{SD}$ & $13.2 \pm 1.5$ & $13.6 \pm 1.8$ & 0.3717 \\
\hline Preop Oxygen Saturation $(\%) \pm$ SD & $96.9 \pm 1.7$ & $96.9 \pm 1$ & 0.7648 \\
\hline Number of Preop Comorbidities \pm SD & $2.9 \pm 1.6$ & $3.9 \pm 2.5$ & 0.0074 \\
\hline Coronary Artery Disease, n (\%) & $15(16.5)$ & $3(20)$ & 0.9999 \\
\hline Diabetes, n (\%) & $11(12.1)$ & $3(20)$ & 0.4146 \\
\hline Hypertension, n (\%) & 67 (73.6) & $14(93.3)$ & 0.1137 \\
\hline Hyperlipidemia, n (\%) & $38(41.8)$ & $9(60)$ & 0.2627 \\
\hline $\mathrm{BPH}^{2}, \mathrm{n}(\%)$ & $16(17.6)$ & $1(6.7)$ & 0.4561 \\
\hline Incontinence, n (\%) & $14(15.4)$ & $1(6.7)$ & 0.4681 \\
\hline $\operatorname{GERD}^{3}, \mathbf{n}(\%)$ & $30(33)$ & $7(46.7)$ & 0.3824 \\
\hline
\end{tabular}

* p-Value from Wilcoxon Rank Sum test comparing Sleep Apnea Groups

${ }^{1}$ American Society of Anesthesiologists

2 Benign prostatic hyperplasia

${ }^{3}$ Gastroesophageal reflux disorder

${ }^{4}$ Mini-mental state examination

${ }^{5}$ Total Knee Arthroplasty 
Table 3

CPAP Treatment Profile of Sleep Apnea Patients

\begin{tabular}{|l|c|c|c|}
\hline CPAP $^{\boldsymbol{I}}$ Usage & $\begin{array}{c}\text { Delirious } \\
(\mathbf{N}=\mathbf{8})\end{array}$ & $\begin{array}{c}\text { Non-Delirious } \\
(\mathbf{N}=7)\end{array}$ & p-Value* $^{*}$ \\
\hline Home Use, $\mathbf{n}(\%)$ & $4(50)$ & $4(57)$ & 0.9999 \\
\hline Hospital Use, $\mathbf{n}(\%)$ & $2(25)$ & $4(57)$ & 0.3147 \\
\hline
\end{tabular}

p-value from Pearson chi-square test

${ }^{1}$ Continuous positive airway pressure 